Proceedings

\title{
Studying the Reaction of Peroxynitrite with Myoglobin for Meat Extract Samples Using Cobalt Phthalocyanine-modified Screen Printed Carbon Electrodes and a Flow Injection Analysis System +
}

\author{
Ioana Silvia Hosu ${ }^{1}$, Diana Constantinescu-Aruxandei ${ }^{1}$, Florin Oancea ${ }^{1}$ and Mihaela Doni ${ }^{2 *}$ \\ 1 National Institute for Research \& Development in Chemistry and Petrochemistry - ICECHIM, \\ Bioproducts Department, 202 Spl. Independentei, Sector 6, Bucharest, Romania; ioana.hosu@icechim.ro \\ (I.S.H.), diana.constantinescu@icechim.ro (D.C.-A.), florin.oancea@icechim.ro (F.O.) \\ 2 National Institute for Research \& Development in Chemistry and Petrochemistry - ICECHIM, \\ Biotechnology and Bioanalysis Department, 202 Spl. Independentei, Sector 6, Bucharest, Romania; \\ mihaela.badea@icechim.ro (M.D.) \\ * Correspondence: mihaela.badea@icechim.ro; Tel.: +40-213-163-063 \\ + Presented at the 1st International Electronic Conference on Biosensors, 2-17 November 2020; Available \\ online: https://iecb2020.sciforum.net/.
}

Received: date; Accepted: date; Published: date

\begin{abstract}
Reactive oxygen/nitrogen species (ROS/RNS) have great impact on cellular response to stress, cell proliferation, cell death, cancer, aging or male infertility. Also, in the food industry and for consumers, as well, it is very important to monitor quality and freshness of raw meat. Different factors are a sign of meat alteration (e.g. discoloration, rancidity, alteration of flavor) [1, 2]. One pathway of alteration is the scavenging activity of myoglobin towards RNS (such as peroxynitrite, PON). This paper presents the development of an electrochemical PON sensor using cobalt phthalocyanine $(\mathrm{CoPc})$ as simple, cost effective, highly thermally stable, biomimetic catalyst and the application of this electrochemical screen-printed carbon electrode (SPCE) based sensor to meat extract samples, using flow injection analysis (FIA). The reduction of peroxynitrite, mediated by $\mathrm{CoPc}$, occurs at a very low potential (around $0.1 \mathrm{~V}$ vs. $\mathrm{Ag} / \mathrm{AgCl}$ pseudoreference), as for higher potentials, the mechanism of mediation changes, and the electro-oxidation of PON is observed. The surface of the modified electrode was characterized using SEM, FTIR and Cyclic Voltametry. The interaction of PON with myoglobin was studied using both UV-Vis and chronoamperometry (at 0.1 $\mathrm{V}$, using the FIA system). The calibration of the electrode was performed: $\operatorname{Ired}(n A)=6.313 \cdot C_{\text {Pon }}(\mu M)$ $+17.469 ;\left(\mathrm{R}^{2}=0.9938\right)$. The calculated LOD was equal to $2.37 \mu \mathrm{M}$ and the linear range was $3-180 \mu \mathrm{M}$. The performance of the electrode can be further improved using a pre-treatment (electro-reduction of the CoPc deposited film, at $-0.3 \mathrm{~V}$, during 60s). This could help us monitor and quantify how much PON was decomposed, when meat extracts are spiked with different PON concentrations, in a highly selective, good sensitive and reproducible way.
\end{abstract}

Keywords: peroxynitrite; electrochemistry; flow injection analysis; FIA; meat extracts; myoglobin; cobalt phthalocyanine; electrochemical reduction; electrocatalysis; screen printed carbon electrode; amperometric detection 


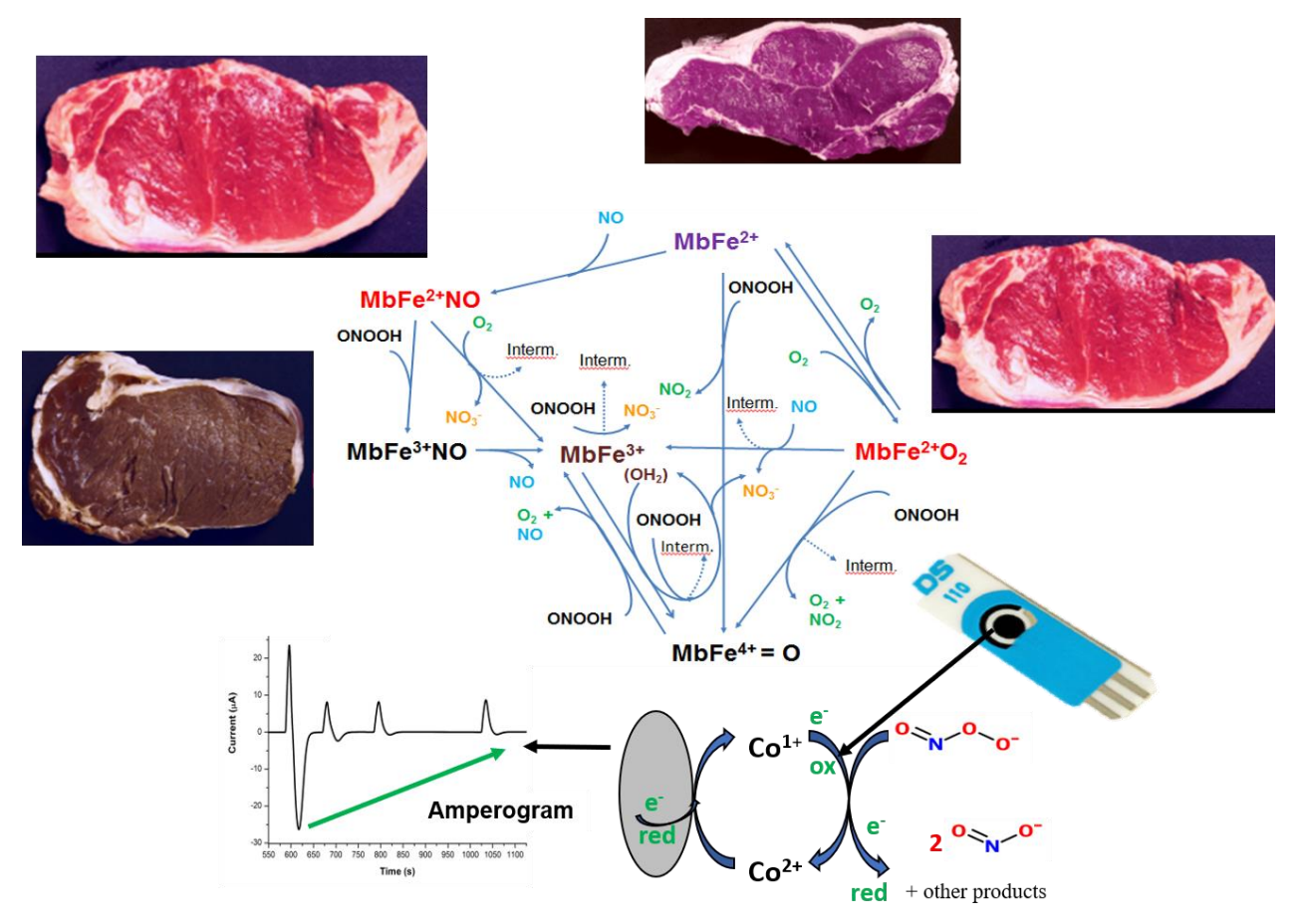

Figure 1. Graphical Abstract. ferrylmyoglobin: $\mathrm{MbFe}^{4+}=\mathrm{O}$, oxymyoglobin: $\mathrm{MbFe}^{2+} \mathrm{O}_{2}$, deoxymyoglobin: $\mathrm{MbFe}^{2+}$, metmyoglobin: $\mathrm{MbFe}^{3+}\left(\mathrm{OH}_{2}\right)$. This is a schematic representation of the chemical reactions of different forms of myoglobin with peroxynitrite and other interfering species/decomposition products. This scheme is not exhaustive.

\section{Introduction}

For the food industry and for the consumers, as well, it is very important to monitor the quality and freshness of raw meat. Different factors are a sign of meat alteration (e.g. discoloration, rancidity, alteration of flavor). One pathway of alteration is the scavenging activity of myoglobin towards nitrooxidative species (such as peroxynitrite, $\mathrm{PON}$ ).

Superoxide dismutase (SOD) eliminates superoxide anion $\left(\mathrm{O}_{2} \bullet-\right)$ with a rate constant of $1-2 \times 10$ $\left.{ }^{9} \mathrm{M}^{-1} \mathrm{~S}^{-1}\right)$, and $\mathrm{NO}$ reacts with $\mathrm{O}_{2} \bullet-$ faster $\left(\approx 10^{10} \mathrm{M}^{-1} \mathrm{~S}^{-1}\right)$, this way competing with SOD for $\mathrm{O}_{2} \bullet$, leading to the formation of a high oxidant molecule: oxoperoxonitrate(1-), or as largely known, peroxynitrite anion $(\mathrm{PON})$. The protonated form of peroxynitrite $(\mathrm{ONOOH})$ has an unusually rapid permeation through membranes, and may induce proteins and lipids damage [3], but in neutral and acidic solutions it decomposes, due to the decomposition of peroxynitrous acid to nitrites and/or nitrates and other oxygen species. The decomposition mechanism and rates depend on $\mathrm{pH}$, temperatures, concentration of peroxynitrite, presence of antioxidants or scavenging species [4].

The ability of iron to change the oxidation state from $\mathrm{Fe}^{2+}$ to $\mathrm{Fe}^{3+}$ has a great effect on the color of the tissue. The binding site of the heme center is also very important [5]. In deoxymyoglobin, $\mathrm{MbFe}^{2+}$, the coordination site is empty, and the meat has a purple color. Binding oxygen to the sixth coordination center, the oxidation state does not change, but the color becomes bright red, forming oxymyoglobin $\left(\mathrm{MbFe}^{2+} \mathrm{O} 2\right)$. The formation of metmyoglobin, $\mathrm{MbFe}^{3+}\left(\mathrm{OH}_{2}\right)$, (iron $3+$ center, the coordination site is empty and the meat has a brown color) can alter the flavor due to lipid and protein oxidation. The aspect of the meat has great impact on consumers and the impact on the food industry is huge [6]. The lack of metmyoglobin $\left(\mathrm{MbFe}^{3+}\left(\mathrm{OH}_{2}\right)\right.$ or metMb) - reducing enzymatic systems in meat after slaughter determines the irreversibility of the oxidation processes of myoglobin [7]. The color changes are also a sign of these processes. Adding nitrites to the raw meat helps keeping the color of the meat bright red, as NO (nitric oxide) can bind to the iron ion in a similar way as the oxygen molecule does. Nitrites and nitrates are also two of the decomposition compounds of peroxynitrite. 
The most used methods to detect peroxynitrite are: high performance liquid chromatography, chemiluminescence, fluorescence spectroscopy, UV-Vis absorbance spectroscopy, electron spin resonance, and electrochemistry [8]. These methods usually use antioxidants like resveratrol, polyphenols or catechins [2], especially in batch analysis, but also using flow injection analysis, for example by injecting antioxidants that can quench the peroxynitrite [9]. The microfluidic injection analysis presents different advantages such as: the presence of laminar flow with no dilution effects, necessity of low volume of analyte (lower than $150 \mu \mathrm{l}$ ), miniaturization, the possibility of real time continuous monitoring (process control), faster and more sensitive response or the possibility of automated processes [10].

Developing an electrochemical sensor able to select between PON and other interfering species in biological tissues would be of interest also for understanding other important issues, such as cancer developing. Several electrochemical sensors are described in the literature $[2,11,12]$. One of the most cited publications involved the electrochemical oxidation of peroxynitrite and the detection at the surface of a single cell [13]. The sensitivities were studied and the authors reported good values, but all the involved processes were oxidations and occurred at potentials higher than $0.5 \mathrm{~V}$, making the electrode more susceptible for signal interferences due to higher probability of other molecules to be oxidized at these potentials.

Only very few reports present the batch reduction of peroxynitrite using a chemically modified electrode: Mn-pDPB (manganese-[poly-2,5-di-(2-thienyl)-1H-pyrrole)-1-(p-benzoicacid)]) catalyzed the reduction of peroxynitrite at $0.2 \mathrm{~V}$, via the electro-oxidation of the metallic site (Sensitivity: 157.0 $\mathrm{nA} \mathrm{mM}{ }^{-1}$, LOD: $1.9 \mathrm{nM}$ ) , and the selectivity and stability is offered by coating the Mn-pDPB with PEI (polyethyleneimine) [14]. Carbon microfibers electrodes modified with manganese(III)[2]paracyclophenylporphyrin catalyze the electro-reduction of released PON from human endothelial cells at $-0.35 \mathrm{~V}$ (LOD: $1 \mathrm{nM}$ ) [15] and (MnTPAc) electropolymerized manganese tetraaminophthalocyanine modified platinum electrode was used for the reduction of synthesized PON in alkaline solution ( $\mathrm{pH} 12$ ) at $-0.45 \mathrm{~V}$ (Sensitivity: $14.6 \mathrm{nA} \mathrm{mM}-1$, LOD: $5 \mu \mathrm{M}$ ) [16]. We also described a poly(2,6-DHN)/SPCE sensor (2,6-dihydroxynaphthalene) based sensor for the oxidation of PON, in alkaline medium [17], but at very low potentials (below $0.15 \mathrm{~V}$ ), with high sensitivity $\left(11.62 \mathrm{nA}^{*} \mathrm{M}^{-1}\right)$ and with $0.2 \mu \mathrm{M}$ LOD, offering very good selectivity. In an earlier work we described the oxidation of PON using a cobalt phtalocyanine tetracarboxylic acid-graphene hybrid, but at higher potentials, with LOD of $1.7 \mathrm{nM}$ [18].

Macrocycle organic compounds (with extended $\pi$ conjugated systems) can act as ligands for different metals, and the usage of these complexes as electrochemical catalysts was and is still encountered in nowadays practice. Phtalocyanines (PCs) were used for the detection of oxidative species [18], due to the high conductivity and different oxidation states of the metallic centers. Also, they have high thermal resistance, they are not toxic and have high redox activity (naval report, the redox activity of MPc). The ring based oxido-reduction processes may influence the catalytic process. Cobalt phtalocyanine is presented to have good sensitivity for a variety of molecules [19] and when the optimal parameters are found, good selectivity could be also achieved.

Herein, we describe the electrochemical reduction of peroxynitrite at $0.1 \mathrm{~V}$, using a commercial cobalt (II) phthalocyanine complex (CoPc) and screen printed carbon electrodes (SPCE). This electrochemical sensor is able to select between the most important interfering species of peroxynitrite (nitrite, nitrate and hydrogen peroxide) and other molecules (e.g. ascorbic acid and dopamine), due to a specific, but simple design, combined with the advantages of a micro-fluidic system. The advantages of using this method over other electrochemical methods will be presented in this paper.

\section{Materials and Methods}

Sodium nitrite, hydrogen peroxide $(30 \%)$, manganese dioxide $(\mathrm{MnO} 2)$, myoglobin from equine skeletal muscle, sodium hydroxide $(\mathrm{NaOH})$, sodium phosphate dibasic dihydrate $\left(\mathrm{Na}_{2} \mathrm{HPO}_{4}{ }^{*} \mathrm{H}_{2} \mathrm{O}\right)$, cobalt (II) phthalocyanine, DMF (dimethylformamide) and $\mathrm{TBATBF}_{4}$ (tetrabutylammonium 
tetrafluoroborate 99\%) were acquired from Sigma Aldrich. Screen printed carbon electrodes were acquired from DropSens, Spain.

Peroxynitrite (PON) was synthesized following a slightly modified procedure [20]. Briefly a solution of $0.7 \mathrm{M} \mathrm{HCl}+0.6 \mathrm{M} \mathrm{H}_{2} \mathrm{O}_{2}$ was added over an ice cooled stirring solution of $0.6 \mathrm{M} \mathrm{NaNO}_{2}$ and almost simultaneously a solution of $3 \mathrm{M} \mathrm{NaOH}$ was added over the mixture, to quench the decomposition of peroxynitrite (a yellow solution). After several reaction minutes, few grams of $\mathrm{MnO}_{2}$ were added to the mixture, to catalyze the decomposition of hydrogen peroxide. After the gas liberation was finished (approximatively $15 \mathrm{~min}$ ), the $\mathrm{MnO}_{2}$ was filtered under vacuum and the solution was divided into small aliquots $(1 \mathrm{ml})$ and stored in the freezer $\left(-20^{\circ} \mathrm{C}\right)$.

The second method of synthesizing PON was to use the gradual release from 10-25 mM 3Morpholinosydnonimine (SIN-1), prepared in a neutral PBS solution, with the help of the oxygen from the atmosphere, according to the reaction presented in the literature [21].The SPCE electrodes were modified by drop casting $2 \mu \mathrm{l}$ of a (cobalt phthalocyanine) CoPc solution ( $1 \mathrm{mg} / \mathrm{ml}$ in DMF). The CoPc solution was prepared by dissolving CoPc in DMF $(1 \mathrm{mg} / \mathrm{ml})$, using ultrasonication during 1 hour (power 100, frequency $37 \mathrm{~Hz}$ ). After the drop-cast, the electrodes were dried at $60^{\circ} \mathrm{C}$, in the oven (for $15 \mathrm{~min}$ ). Before different drop-casting steps, the electrodes were rinsed with DMF and dried with nitrogen. The process was repeated 3 times, without rinsing. The electrode was stabilized by cycling between $-0.6 \mathrm{~V}$ and $0.6 \mathrm{~V}$ (in PBS $\mathrm{pH} 12$ ).

\section{Results}

\subsection{Batch determination of peroxynitrite using SPCE/CoPc electrodes}

\subsubsection{UV-Vis determination of synthesized PON and SIN-1}

The UV-Vis spectrum of synthesized genuine PON is is less complicated than that of SIN-1: molar exctinction coefficient of $1670 \mathrm{M}^{-1} \mathrm{~cm}^{-1}$ can be used to calcultate the concentration at $302 \mathrm{~nm}$ [22]. The main drawback is that a significant amount of nitrite is also produced during this reaction (Figure 2a).

In the case of SIN-1, three absorption peaks can be identified: $212 \mathrm{~nm}, 250 \mathrm{~nm}$ and $280 \mathrm{~nm}$ (Figure $2 \mathrm{~b}$ ). As the $280 \mathrm{~nm}$ peak is usually attributed to the formation of PON (through the reaction of superoxide with nitric oxide), the others are not well explained in literature. [21] Typically a solution of $1 \mathrm{mM} \mathrm{SIN}-1$ releases peroxynitrite at a rate of $1 \mathrm{mM} / \mathrm{min}$. [18]

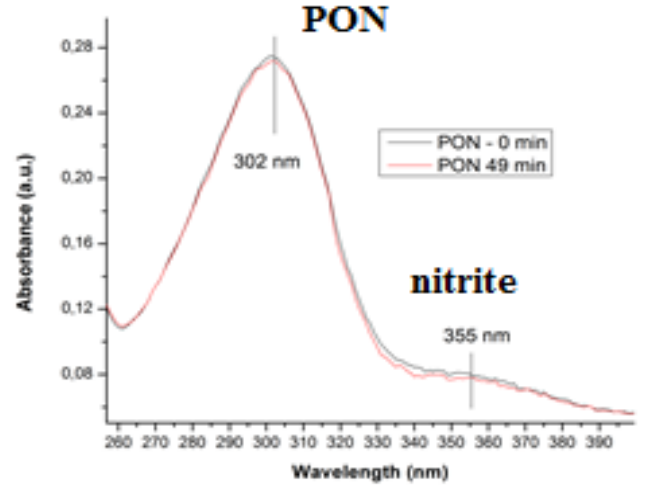

(a)

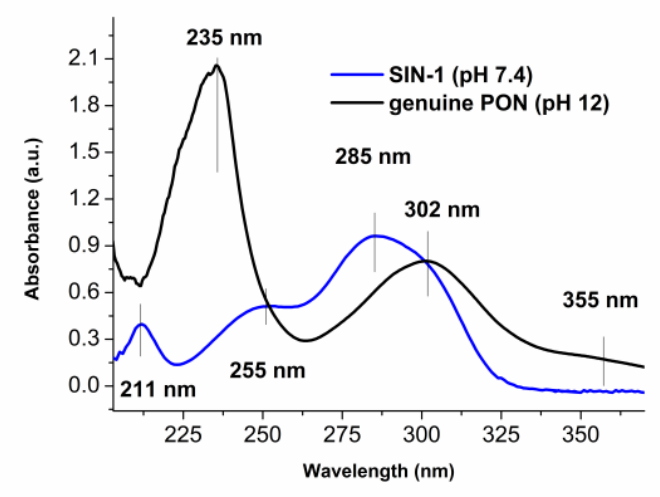

(b)

Figure 1. UV-Vis spectra of (a) genuine PON during time ( $\mathrm{pH} 12)$ and (b) comparison with SIN-1 (pH 7.4).

\subsubsection{Characterization of the deposited CoPc films on the SPCE}

For the detection of peroxynitrite we developed a cost-effective and rapid metod to prepare the sensor based on drop-casting cobalt phthalocyanine on a surface of a screen-printed carbon electrode (SPCE). As the macrocycle has 18 delocalized $\pi$ electrons, thin films could be deposited by dropcasting through $\pi$ stacking, like other materials, such as graphene. As we previously reported [18], 
CoPc presents 2 anodic and 2 cathodic peaks (corresponding to $\mathrm{Co}^{3+} / \mathrm{Co}^{2+}$ and $\mathrm{Co}^{2+} / \mathrm{Co}^{1+}$ redox processes). In this paper, we targeted the exploitation of the $\mathrm{Co}^{2+} / \mathrm{Co}^{1+}$ redox couple (Figure 3a), due to the occurrence at more negative potentials $\left(\mathrm{E}_{0} \sim 0.1 \mathrm{~V}\right)$, than the couple $\mathrm{Co}^{3+} / \mathrm{Co}^{2+}\left(\mathrm{E}_{0} \sim 0.65 \mathrm{~V}\right)$, and because, besides good sensitivity, there is the possibility to reach a remarkable selectivity for peroxynitrite. It can be observed that upon several scans (5 cycles), the electrode reaches a steady state. Similar peaks were observed in the literature [23].

Cyclic voltammetry, in the $-0.6 \mathrm{~V}$ to $0.6 \mathrm{~V}$ range, was used to determine the redox process of peroxynitrite $(\mathrm{PON})$, using the $\mathrm{SPCE} / \mathrm{CoPc}$ electrode, at $\mathrm{pH}$ 9. The redox process involving peroxynitrite takes place at around $0.1 \mathrm{~V}$, with $\mathrm{Ec}=0.047$ and $\mathrm{Ea}=0.072(\Delta \mathrm{E}=25 \mathrm{mV})$, but small current in the reduction, suggesting that the oxidation may be irreversible. The calculated formal potential is $0.06 \mathrm{~V}$. Also, under another probable mechanism, an irreversible reduction takes place around $-0.3 \mathrm{~V}$, probably involving also the chemical oxidative reaction of peroxynitrite over the metallic center: cobalt being chemically oxidized by PON, is being electro-reduced, with a higher current, depending on the concentration of PON (Figure 3b).

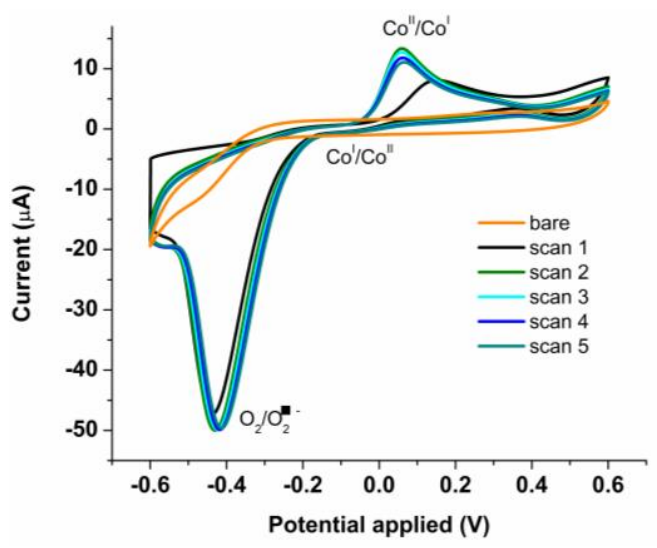

(a)

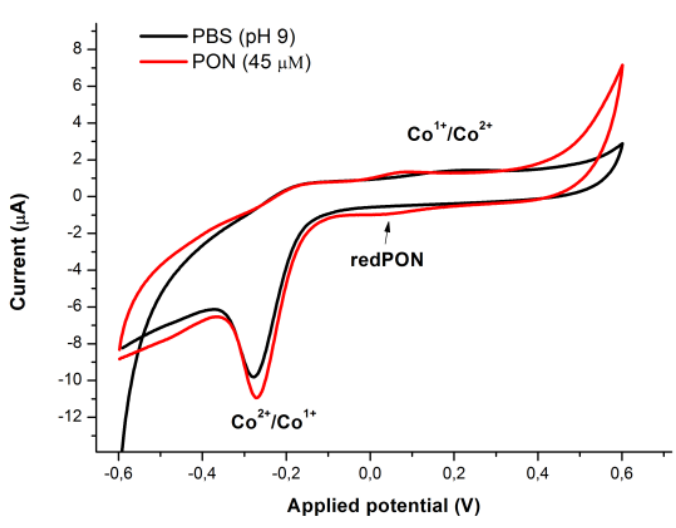

(b)

Figure 2. CV of (a) the SPCE/CoPc electrode upon different scans, in PBS pH 12. The oxido-reduction processes are presented for the cobalt metallic center. (b) Cyclic voltammetry registered using the SPCE/CoPc electrode in the absence (black) and in the presence (red) of $45 \mu \mathrm{M}$ PON (scan rate $9 \mathrm{mV} / \mathrm{s}$ ), PBS pH 9.

When the morphology is studied with SEM (Figure 4a and $4 \mathrm{~b}$ ), it can be observed that, in accordance to the literature too, the CoPc molecules tend to form random agglomerates [24], of various sizes (between $0.4 \mu \mathrm{m}$ and $10 \mu \mathrm{m}$ in length and few hundreds nm in thickness and width) depending on the surface used for the deposition.

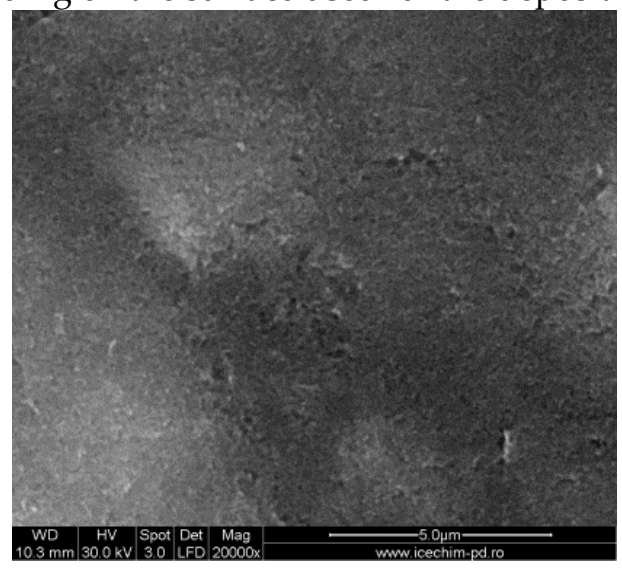

(a)

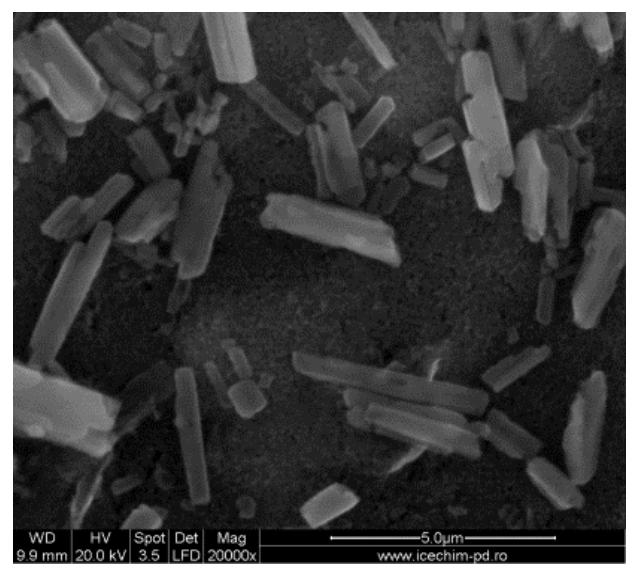

(b) 


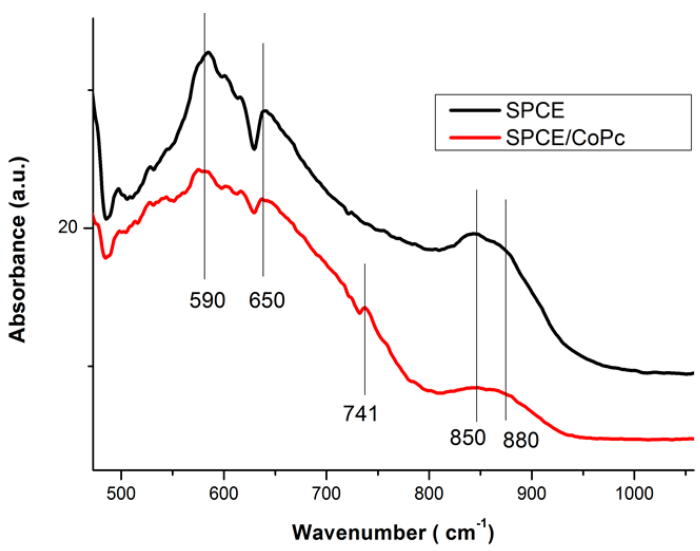

(c)

Figure 3. SEM characterization of the (a) unmodified SPCE and (b) SPCE/CoPc. (c) FT-IR spectra of unmodified SPCE and modified SPCE with CoPc (SPCE/CoPc).

The FT-IR analysis (Figure 4c) proves the presence of CoPc on the surface of the electrode, especially due to the $741 \mathrm{~cm}^{-1}$ band in the fingerprint region, corresponding to phthalocyanine in plane vibrations [25]. Other vibrations belonging to the graphitic structure of SPCE, are also observed: deformation of C-C out of aromatic plane $\left(650 \mathrm{~cm}^{-1}\right)$, vibrations of $\mathrm{C}-\mathrm{H}$ in the aromatic plane (850 and $\left.808 \mathrm{~cm}^{-1}\right)$ or the vibrations of $\mathrm{C}=\mathrm{C} \mathrm{sp}{ }^{2}\left(1610 \mathrm{~cm}^{-1}\right)$.

\subsubsection{Batch Optimization of the CoPc modified electrodes for PON detection}

As presented in Figure 5a, an apparent irreversible redox process occurs $(\triangle \mathrm{E}=150 \mathrm{mV})$ upon scanning in cyclic voltammetry of $170 \mu \mathrm{M}$ PON, in PBS pH 12, using the SPCE/CoPc electrode, in the $-0.2 \mathrm{~V}-0.6 \mathrm{~V}$ range. The oxidation is shifted to higher oxidation potentials, when the buffer is PBS $\mathrm{pH} 9$, and the process seems to be mostly an irreversible oxidation, from the cyclic voltammetry (Figure 5b).

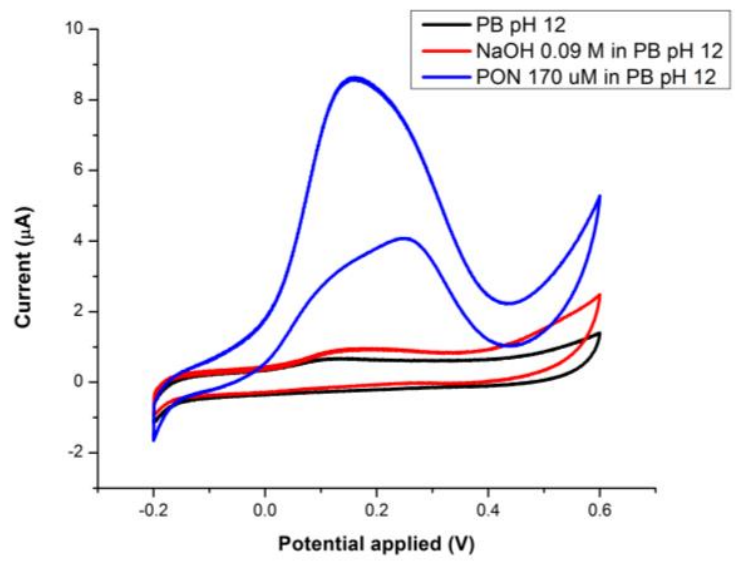

(a)

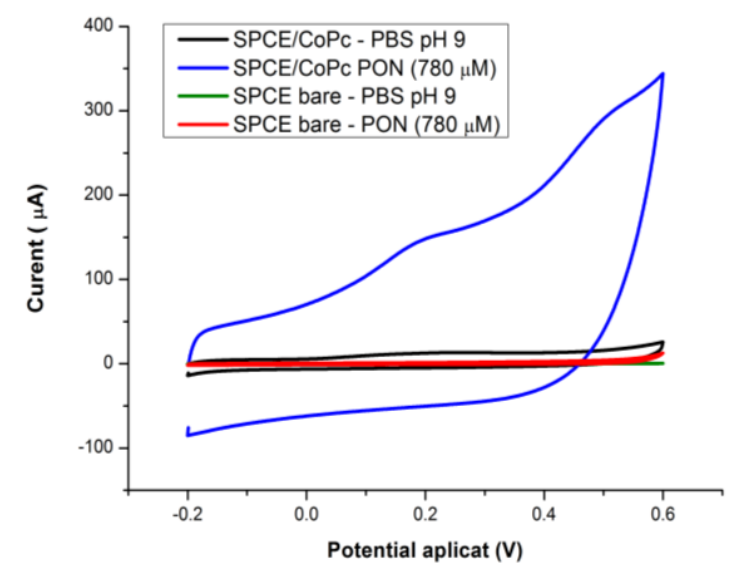

(b)

Figure 4. CV of bare SPCE (black and green) and SPCE/CoPc (blue and red) electrode for PON, in (a) PBS pH 12 $(170 \mu \mathrm{M}$ PON) and (b) in PBS pH $9(780 \mu \mathrm{M}$ PON), at a scan rate of $100 \mathrm{mV} / \mathrm{s}$.

Interfering species (ascorbic acid, nitrite and nitrate, $100 \mu \mathrm{M}$ ) were also studied using cyclic voltammetry and a CoPc modified GCS and compared with $100 \mu \mathrm{M}$ PON (Figure 6). Electro-catalytic oxidation occurs for ascorbic acid at around $0.4 \mathrm{~V}$ (in good accordance with literature [26], but this peak appears due to direct electrochemical oxidation of ascorbic acid on the bare underlying electrode, not to electro-catalysis with $\mathrm{CoPc}$ ). Hydrogen peroxide usually occurs around $0.6 \mathrm{~V}$, not interfering with the PON oxidation on GCE/CoPc around $0.1 \mathrm{~V}$ (as already described above). This means that 
using potentials around $0.1 \mathrm{~V}$ we have a very good selectivity towards PON. Nitrite did not have any response using the CoPc modified GCE [27].

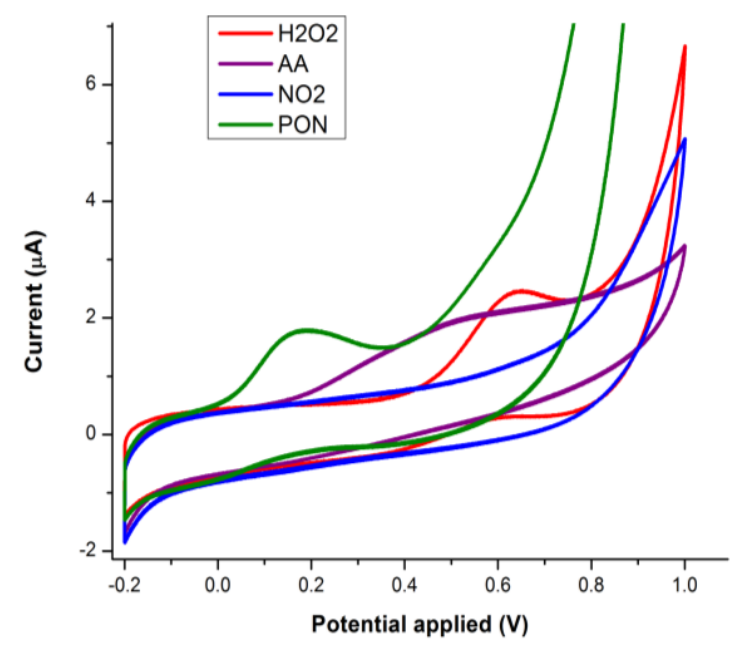

Figure 5. Evaluation of the interfering species using $\mathrm{CV}$ for $100 \mu \mathrm{M}$ peroxynitrite (PON - green): $100 \mu \mathrm{M}$ ascorbic acid (AA- purple), $100 \mu \mathrm{M}$ hydrogen peroxide $\left(\mathrm{H}_{2} \mathrm{O}_{2}-\right.$ red), $100 \mu \mathrm{M}$ nitrite $\left(\mathrm{NO}_{2}-\right.$ blue), using a GCE/CoPc electrode.

Differential pulse voltammetry revealed that, upon reduction of the CoPc films, by starting the scans from more and more negative potentials, the cumulative current (both cathodic and anodic) increases (Figure 7a). This suggests that pre-treatment of the electrode could improve the response of the electrode for PON, because of the reduction of $\mathrm{Co}^{2+}$ to $\mathrm{Co}^{1+}$. Also, the shape of the DPV peak suggests that, besides diffusion, other processes occur (e.g. adsorption of product or reactant molecules, on the surface of the electrode or even the coordination of the ONOO-molecule to the metallic catalytic center).

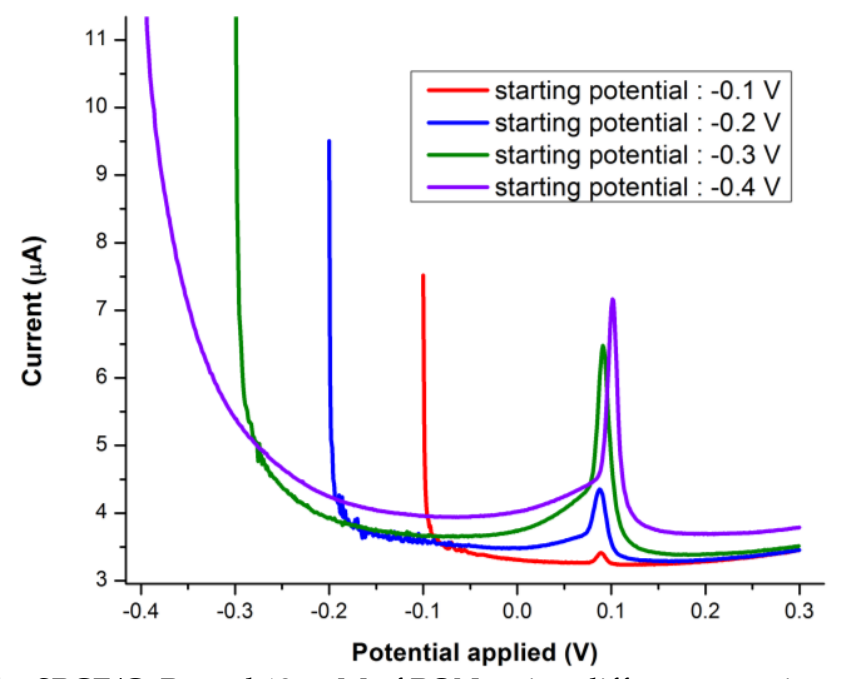

Figure 6. (a) DPV of the SPCE/CoPc and $125 \mu \mathrm{M}$ of PON, using different negative starting potentials.

\subsection{FIA optimization of the SPCE/CoPc electrodes for PON detection.}

FIA analysis gave us the opportunity to develop a very selective sensor for PON (Figure 8a). It can be clearly observed that changing the applied potentials in chronoamperometry $(0.0,0.1$ and 0.25 $\mathrm{V})$ helped us to determine that the reduction of PON occurs from $0.1 \mathrm{~V}$. Due to the several other advantages already described, a single line flow injection system was employed for further experiments. 


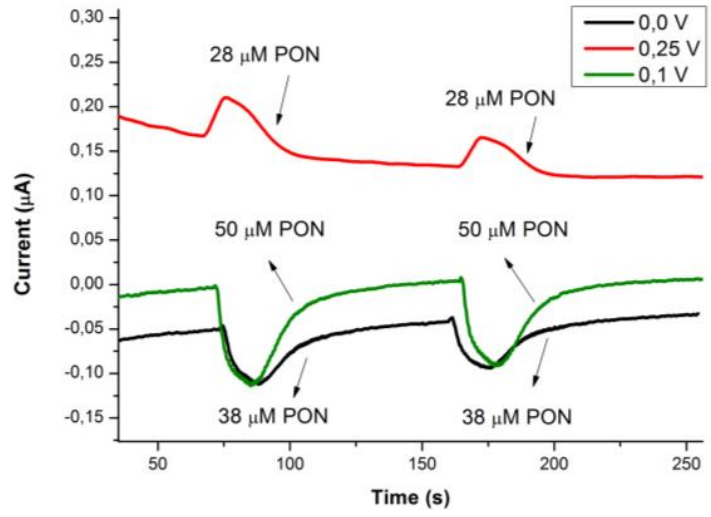

(a)

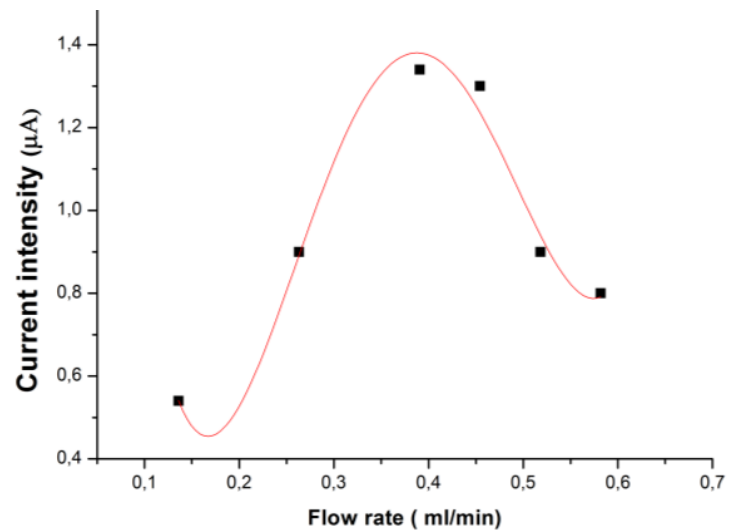

(b)

Figure 7. (a) CA spectra of the FIA analysis using different potentials: $0.0 \mathrm{~V}$ (black), $0.1 \mathrm{~V}$ (green) and $0.25 \mathrm{~V}$ (red). (b) Study of the flow rate (ml/min) influence over the current intensity of $200 \mu \mathrm{M}$ PON (PBS pH 12). This $\mathrm{pH}$ was used due to the high stability of PON.

To determine the optimum flow rate, $200 \mu \mathrm{M}$ of PON, in PBS pH 12 was injected while amperometry at $0.1 \mathrm{~V}$ was performed. This $\mathrm{pH}$ was used to keep the concentration constant during the measurements $(200 \mu \mathrm{M})$, because PON is very stable at this $\mathrm{pH}$. The curve was fitted with $\mathrm{R}^{2}$ 0.9195 with a fourth-grade polynomial function. A flow rate of $0.4 \mathrm{ml} / \mathrm{min}$ and a voltage of $0.1 \mathrm{~V}$, were used to further optimize the detection process (Figure $8 \mathbf{b}$ ).

The calibration (Figure 8a) of the electrode was performed: $\operatorname{Ired}(n A)=6.313 \cdot C_{\mathrm{PoN}}(\mu \mathrm{M})+17.469$; $\left(R^{2}=0.9938\right)$, using the FIA system and chronoamperometry at $0.1 \mathrm{~V}$ (Figure $\left.9 \mathbf{b}\right)$. The calculated LOD was equal to $2.37 \mu \mathrm{M}$ and the linear range is $3-180 \mu \mathrm{M}$. When a low concentration was used $(50 \mu \mathrm{M})$, the reproducibility varied from $95 \%$ to $99 \%$ and the RSD (for three replicates) for each calibration concentration did not exceed $10 \%$. These parameters are very good taking in consideration that the screen printed carbon electrodes are usually disposable electrochemical devices (that usually can be used just for few measurements) and that the analyte is a quite unstable oxidative anion.

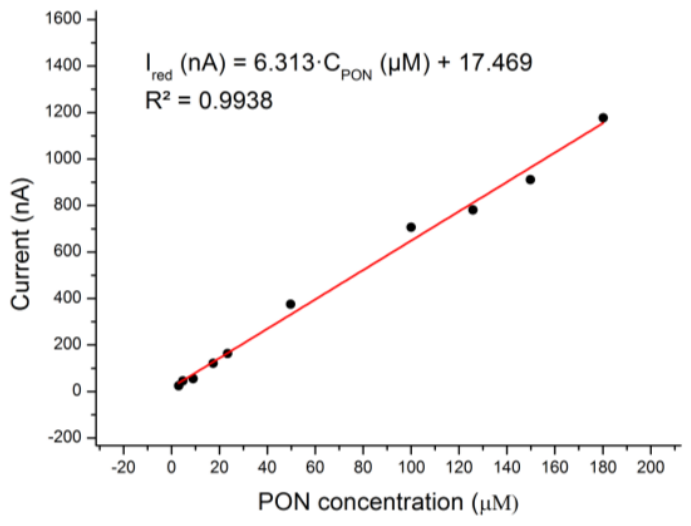

(a)

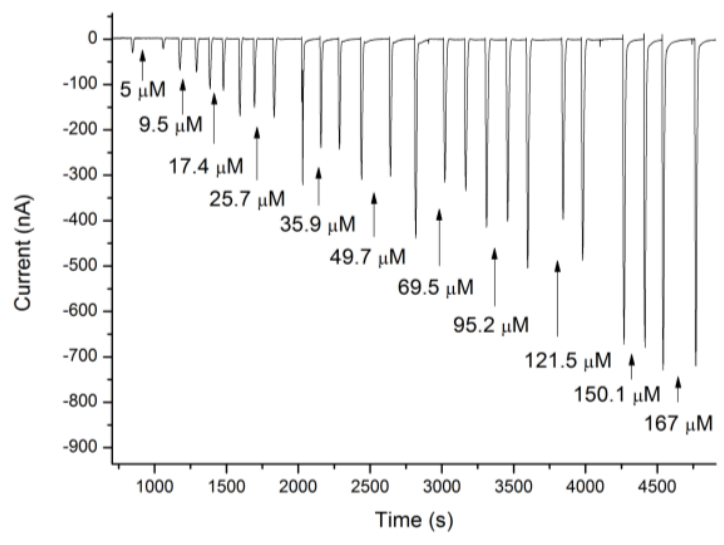

(b)

Figure 8. (a) Calibration curve of the SPCE/CoPc electrode for PON, PBS pH 9. (b) Chronoamperogram measured using the FIA system and the SPCE/CoPc electrode, $\mathrm{E}=0.1 \mathrm{~V}$, flow rate $=0.4 \mathrm{ml} / \mathrm{min}$.

\subsection{Studying the reaction of myoglobin in buffered solution and peroxynitrite, using FIA}

Due to the probability to find myoglobin under different forms in meat extracts, (Error! Reference source not found.) the conversion of metMb (metmyoglobin) to myoglobin (reduced myoglobin, redMb or $\mathrm{MbFe}^{2+} \mathrm{O}_{2}$ ) can be followed as a consequence of $\mathrm{PON}$ scavenging. The changes in the UV-Vis absorption spectra are described in literature: the concentration of the $\mathrm{MbFe}^{2+} \mathrm{O}_{2}$ solutions can be verified by measuring the absorbance at 417,542 , and/or $580 \mathrm{~nm}\left[\varepsilon 417=128 \mathrm{mM}^{-1} \mathrm{~cm}^{-}\right.$ $1, \varepsilon_{542}=13.9 \mathrm{mM}^{-1} \mathrm{~cm}^{-1}$ and $\left.\varepsilon_{580}=14.4 \mathrm{mM}^{-1} \mathrm{~cm}^{-1}\right]$ [28] and the spectrum of metMb has a maximum of absorbance at $502\left[\varepsilon_{502}=10.2 \mathrm{mM}^{-1} \mathrm{~cm}^{-1}\right]$ and $630 \mathrm{~nm}$ at $\mathrm{pH}$ 6.4, and the Soret band absorbance maximum is at $408 \mathrm{nM}$ at $\mathrm{pH} 7.4$ [29]. The reduction of metMb $(25 \mu \mathrm{M})$ was performed using $75 \mathrm{mM}$ 
of $\left(\mathrm{NaBH}_{4}\right)$ in PBS pH 9 and the reaction was followed spectrophotometrically. After the reaction, a gel filtration Sephadex G 25 column was used to separate the borohydride from the redMb.

Initially, metMb was used to follow the reaction with peroxynitrite. The fingerprint of metMb in chronoamperometry (the presence of the double peak, meaning 2 reduction processes consecutively, Figure 10 zoom) can be very useful to identify this compound and to distinguish it from redMb or ferrylMb. Using a ratio of metMb/PON of $1 / 5$ (suitable for the peroxynitrite to oxidize metMb), one can observe in chronoamperogram from Figure 10, that incubating $400 \mu \mathrm{M}$ PON with $80 \mu \mathrm{M}$ metMb, the measured current corresponds to the quantification limit of PON with the electrode used $(\mathrm{LOQ}=12.5 \mu \mathrm{M})$. Other oxidation processes can be observed during the increase of incubation time, but they do not interfere with the reduction of PON signals.

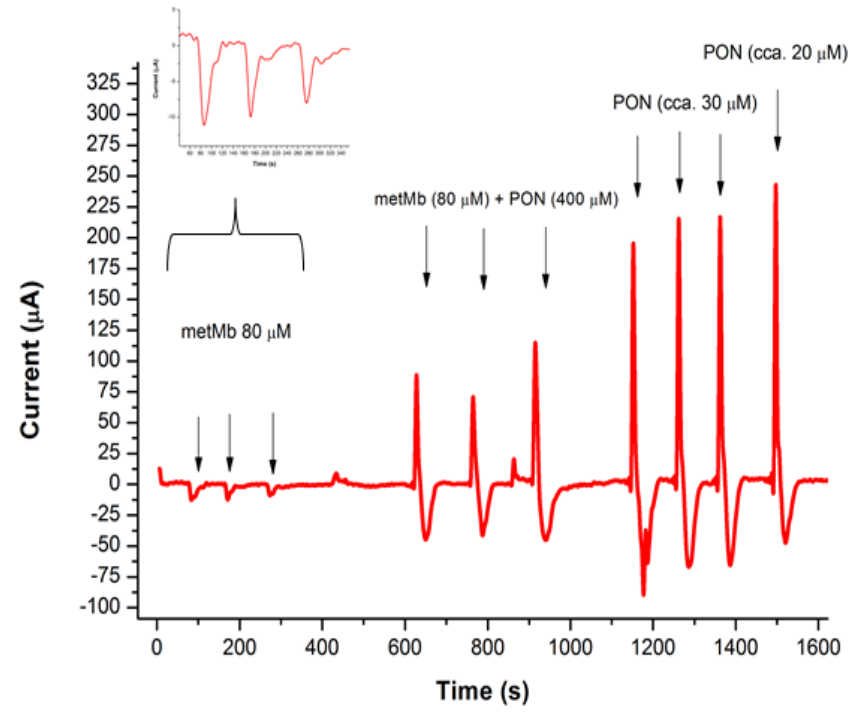

Figure 10. The amperometric response of the SPCE/CoPc $(E=0.1 \mathrm{~V})$ for $80 \mu \mathrm{M}$ metMb, $80 \mu \mathrm{M}$ metMb incubated with $400 \mu \mathrm{M}$ PON and 30, respectively, $20 \mu \mathrm{M}$ PON.

Different concentrations of PON were incubated with metMb $20 \mu \mathrm{M}$. Figure 11a presents the amperometric response at different interval times of incubation and a decrease of signal can be observed, after 4 minutes of incubation the current remaining stable due to partial consumption of PON (Figure 11b). The measurements conducted at 0 s correspond to the solutions having the initial/maximum concentration of PON $(200$ or $100 \mu \mathrm{M})$, before mixing them with the $20 \mu \mathrm{M}$ solution of metMb. The recovered PON concentrations were correlated to the UV-Vis measurements at 302 nm.

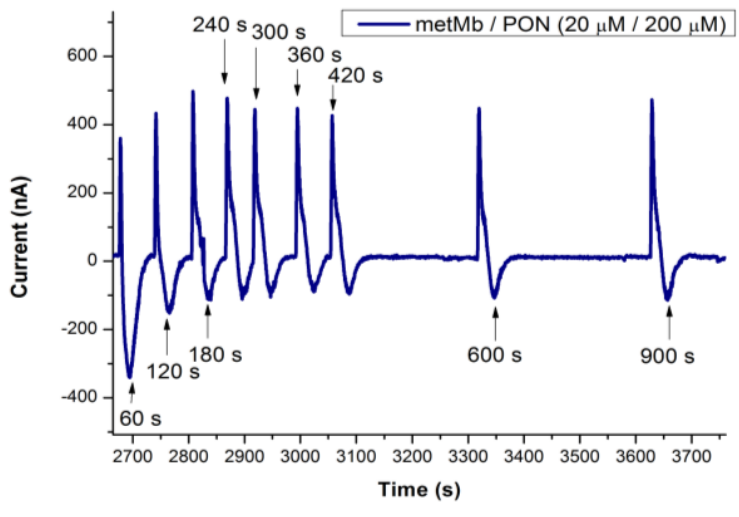

(a)

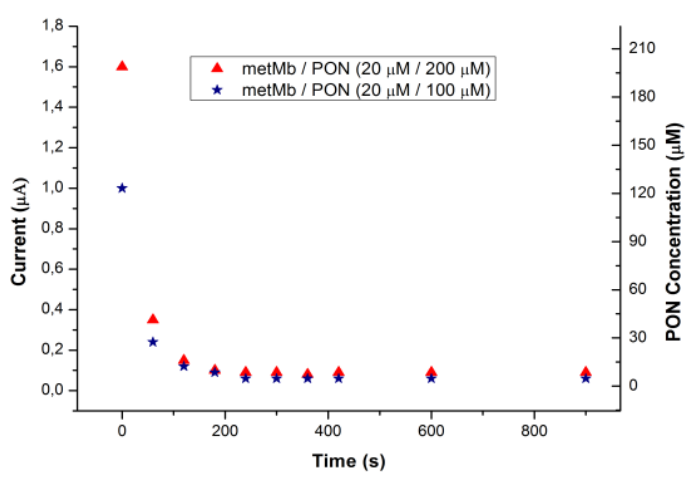

(b)

Figure 9. The influence of the incubation time on the amperometric response generated by the mixture between $20 \mu \mathrm{M}$ metMb and $200 \mu \mathrm{M}$ PON (a) and the equivalent currents registered for different time periods of incubation of $20 \mu \mathrm{M}$ metMb with 200, respectively $100 \mu \mathrm{M}$ PON, in PON concentrations (b). 


\section{Discussion}

Detecting reactive oxygen and nitrogen species is of great importance for many domains. Peroxynitrite, despite being a short half-life oxidative species, induces powerful oxidative stress effects on cells. Scavengers are important tools to eliminate this oxidative stress. Myoglobin is one of the scavengers, as it is an oxygen-binding protein from the heme group. Cobalt phtalocyanine was already used in literature as a bio-mimetic material for biosensors [30]. It has similar scavenging role when it comes to PON. As the metal cobalt center of the heme, similar to iron, has multiple oxidation states, the reduction of $\mathrm{PON}$ seems to be catalyzed by $\mathrm{CoPc}$ through redox reactions. We demonstrate here that the $\mathrm{Co}^{2+} / \mathrm{Co}^{1+}$ redox couple is more effective than the high potential electrochemical methods reported in the literature for the electrochemical detection of PON, as it offers better selectivity. Cyclic voltammetry as well as other techniques (linear sweep voltammetry or differential pulse voltammetry) was used to determine that this redox reaction of PON is apparently an irreversible process.

Our research involved the hypothesis that upon the electro-oxidation of $\mathrm{Co}^{1+}$ to $\mathrm{Co}^{2+} \mathrm{a}$ simultaneously occurring process can also take place (the reduction of peroxynitrite to nitrite). Starting from this hypothesis, an important issue was to understand how to overcome the apparent irreversible oxidation of PON from batch electrochemical analysis. The ability of flow injection analysis in understanding reaction mechanisms and complicated electrode kinetics [31] served as an important tool to select between the oxidation potential of peroxynitrite (and of other species) and the reduction potential of peroxynitrite because it became easier to identify each. Using this single line flow injection system and chronoamperometric method at low potentials (around $0.1 \mathrm{~V}$ ), we were able to obtain good sensitivity $(\mathrm{LOD}=2.37 \mu \mathrm{M})$. Comparing to literature, this is one of the few articles based on the electro-catalyzed reduction of PON. Even though we obtained lower sensitivity (2.37 $\mu \mathrm{M}$ compared to $1.9 \mathrm{nM}$ [14] and $1.0 \mathrm{nM}$ [32]), but higher than $5 \mu \mathrm{M}$ [33], we achieved a much better selectivity against all the important interfering species (ascorbic acid, hydrogen peroxide, nitrate and nitrite) at biological concentrations. Understanding better the different aspects of the electrochemical process could help improve the analytical characteristics of the electrode.

Calibration was possible for detection of PON also in the presence of another scavenger: myoglobin. Literature presents the fact that the PON to redMb ratio must be 1:10 for efficient scavenging and that metMb is less efficient in scavenging PON (as the metal center is already oxidized). We studied the reaction of $\mathrm{PON}$ with metMb, as myoglobin in meat is more likely present as metMb. Using different concentrations of $\mathrm{PON}$, we were able to determine the consumption of PON by the scavenging mechanism of metMb. For further studies, reduced myoglobin should be also used for PON consumption, in buffered solution. Meat extracts should be reacted with PON in the same manner as buffered solutions. Similar chronoamperometric responses are expected. This kind of reactions should be followed simultaneously by UV-Vis to quantify the metMb and redMb during/after completion of reactions.

Further optimizations and studies need to be performed to determine the reactions that take place at the surface of the electrode. The amount of the CoPc deposited on the surface of the SPCE should be also optimized for the detection of PON and the surface coverage percentage should be calculated. Determining the effect of different scan rates on the SPCE/CoPc electrode in the absence or in the presence of PON could also help us determine if the electrochemical reaction is a diffusion or adsorption-controlled reaction. As the experiments performed in this paper suggest a positive effect of reducing the cobalt metal center before the detection of PON, pre-treatment of the electrode might be necessary, and this has to be studied in a more detailed manner.

Another further research direction is to use the already described hybrid materials (CoPcgraphene), in order to increase the solubility of the hybrid material in aqueous solvents and electron transfer at the surface of the electrode. 


\section{Conclusions}

Our label-free electrochemical method proposes a cobalt phtalocyanine deposition on the screen printed carbon electrode for the direct detection of peroxynitrite. This method is simple, sensitive, highly selective, rapid and cost-effective.

The SPCE/CoPc electrode was fully characterized and optimized for the detection of peroxynitrite. The linear range is from $3 \mu \mathrm{M}$ to $180 \mu \mathrm{M}$ and the limit of detection is $2.37 \mu \mathrm{M}$, making this electrode suitable for biological matrices. Moreover, further optimization of this electrode, before usage, may be the reduction of the CoPc film deposited on the electrode (using the sodium borohydride chemical method or by an electrochemical method).

The SPCE/CoPc could be a suitable electrode to monitor the reaction between peroxynitrite and myoglobin in situ and in vitro, but further optimization should be done for more accurate quantitative measurements. The scavenging reaction of myoglobin (in the form of metMB), with PON, decreased the amount of PON, and this decrease was measured/ quantified with our SPCE/CoPc electrode.

We propose a simple method that has great impact on the PON sensor pool, as it can be used to quantify PON in a complex media: meat samples.

Author Contributions: conceptualization, M.B.D. and I.S.H; methodology I.S.H., investigation, I.S.H. and D.C.A.; project administration, M.B.D. and F.O.; supervision, M.B.D. and F.O.; validation, M.B.D., visualization, M.B.D. and I.S.H., writing - original draft preparation, I.S.H.; writing - review and editing, M.B.D., I.S.H., D.C.A. and F.O.;

Funding: This work was funded by the Romanian National Authority for Scientific Research and Innovation, CNCS-UEFISCDI, Project PN-II-ID-PCE-2011-3-1076, Contract no. 184/2011. The authors also acknowledge the financial support by The Ministry of Research and Innovation, Nucleu Programme ChemEmergent, Project PN.19.23.01.01, Integrated platform for the smart valorization of biomass - Smart-Bi.

Acknowledgments: The authors are grateful to Ghiurea Marius for SEM images, Sanda Doncea for FTIR measurements, Alina Vasilescu for all the advices and the cobalt phtalocyanine.

Conflicts of Interest: The authors declare no conflict of interest.

\section{References}

1. Exner, M.; Herold, S. Kinetic and mechanistic studies of the peroxynitrite-mediated oxidation of oxymyoglobin and oxyhemoglobin. Chem. Res. Toxicol. 2000, 13, 287-293, doi:10.1021/tx990201k.

2. Vasilescu, A.; Vezeanu, A.; Liu, Y.; Hosu, I. S.; Worden, R. M. and Peteu, S. F. Meat freshness: Peroxynitrite's oxidative role, its natural scavengers, and new measuring tools. In Instrumental methods for the analysis and identification of bioactive molecules. G. K. Jayprakasha; B. S. Patil and F. Pellati. Acs symposium series. 1185. Washington: Amer Chemical Soc, 2014, 303-32.

3. Carlsen, C.U.; Møller, J.K.; Skibsted, L.H. Heme-iron in lipid oxidation. Co-ord. Chem. Rev. 2005, 249, 485498, doi:10.1016/j.ccr.2004.08.028.

4. Kubant, R.; Malinski, C.; Burewicz, A.; Malinski, T. Peroxynitrite/Nitric Oxide Balance in Ischemia/Reperfusion Injury-Nanomedical Approach. Electroanal. 2006, 18, 410-416, doi:10.1002/elan.200503436.

5. Connolly, B.J.; Brannan, R.G.; Decker, E.A. Potential of Peroxynitrite To Alter the Color of Myoglobin in Muscle Foods. J. Agric. Food Chem. 2002, 50, 5220-5223, doi:10.1021/jf020289z.

6. Connolly, B.J.; Decker, E.A. Peroxynitrite induced discoloration of muscle foods. Meat Sci. 2004, 66, 499505, doi:10.1016/s0309-1740(03)00153-0.

7. Jeong, J.-Y.; Kim, G.-D.; Yang, H.-S.; Joo, S.-T. Pigments and Color of Muscle Foods. In Methods in Food Analysis; Informa UK Limited, 2014; pp. 44-61.

8. Li, M.; Gong, X.; Li, H.-W.; Han, H.; Shuang, S.; Song, S.; Du, F. A fast detection of peroxynitrite in living cells. Anal. Chim. Acta 2020, 1106, 96-102, doi:10.1016/j.aca.2020.02.009.

9. Wada, M.; Kira, M.; Kido, H.; Ikeda, R.; Kuroda, N.; Nishigaki, T.; Nakashima, K. Semi-micro flow injection analysis method for evaluation of quenching effect of health foods or food additive antioxidants on peroxynitrite. Lumin- 2010, 26, 191-195, doi:10.1002/bio.1206.

10. Ruzicka, J. Flow injection analysis ? A survey of its potential as solution handling and data gathering technique in chemical research and industry. Anal. Bioanal. Chem. 1988, 329, 653-655, doi:10.1007/bf00624768. 
11. Vasilescu, A.; Gheorghiu, M.; Peteu, S. Nanomaterial-based electrochemical sensors and optical probes for detection and imaging of peroxynitrite: a review. Microchim. Acta 2017, 184, 649-675, doi:10.1007/s00604017-2093-7.

12. Vasilescu, A.; Dinca, V.; Filipescu, M.; Rusen, L.; Hosu, I.S.; Boukherroub, R.; Szunerits, S.; Dinescu, M.; Peteu, S. CHAPTER 9. Recent Approaches to Enhance the Selectivity of Peroxynitrite Detection. In Detection Science; Royal Society of Chemistry (RSC), 2015; pp. 166-185.

13. Amatore, C.; Arbault, S.; Bruce, D.; de Oliveira, P.; Erard, M. and Vuillaume, M. Characterization of the electrochemical oxidation of peroxynitrite: Relevance to oxidative stress bursts measured at the single cell level. Chemistry-a European Journal 2001, 7, 4171-4179. 10.1002/1521-3765(20011001)7:193.0.c0;2-5. .

14. Koh, W.C.A.; Son, J.I.; Choe, E.S.; Shim, Y.-B. Electrochemical Detection of Peroxynitrite Using a Biosensor Based on a Conducting Polymer-Manganese Ion Complex. Anal. Chem. 2010, 82, 10075-10082, doi:10.1021/ac102041u.

15. Mason, R.P.; Jacob, R.F.; Corbalan, J.J.; Szczesny, D.; Matysiak, K.; Malinski, T. The favorable kinetics and balance of nebivolol-stimulated nitric oxide and peroxynitrite release in human endothelial cells. BMC Pharmacol. Toxicol. 2013, 14, 48, doi:10.1186/2050-6511-14-48.

16. Cortés, J.S.; Granados, S.G.; Ordaz, A.A.; Jiménez, J.A.L.; Griveau, S.; Bedioui, F. Electropolymerized Manganese Tetraaminophthalocyanine Thin Films onto Platinum Ultramicroelectrode for the Electrochemical Detection of Peroxynitrite in Solution. Electroanal. 2007, 19, 61-64, doi:10.1002/elan.200603703.

17. Hosu, I.S.; Constantinescu-Aruxandei, D.; Jecu, M.-L.; Oancea, F.; Doni, M. Peroxynitrite Sensor Based on a Screen Printed Carbon Electrode Modified with a Poly(2,6-dihydroxynaphthalene) Film. Sensors 2016, 16, 1975, doi:10.3390/s16111975.

18. Hosu, I.S.; Wang, Q.; Vasilescu, A.; Peteu, S.F.; Raditoiu, V.; Railian, S.; Zaitsev, V.; Turcheniuk, K.; Wang, Q.; Li, M.; et al. Cobalt phthalocyanine tetracarboxylic acid modified reduced graphene oxide: a sensitive matrix for the electrocatalytic detection of peroxynitrite and hydrogen peroxide. RSC Adv. 2015, 5, 14741484, doi:10.1039/c4ra09781e.

19. Boni, A.C.; Wong, A.; Dutra, R.A.F.; Sotomayor, M.D.P.T. Cobalt phthalocyanine as a biomimetic catalyst in the amperometric quantification of dipyrone using FIA. Talanta 2011, 85, 2067-2073, doi:10.1016/j.talanta.2011.07.038.

20. Robinson, K.M.; Beckman, J.S. Synthesis of Peroxynitrite from Nitrite and Hydrogen Peroxide. In Methods in Enzymology; Elsevier BV: Amsterdam, The Netherlands, 2005; Vol. 396, pp. 207-214.

21. Singh, R.J.; Hogg, N.; Joseph, J.; Konorev, E.; Kalyanaraman, B. The Peroxynitrite Generator, SIN-1, Becomes a Nitric Oxide Donor in the Presence of Electron Acceptors. Arch. Biochem. Biophys. 1999, 361, 331339, doi:10.1006/abbi.1998.1007.

22. Ischiropoulos, H.; Al-Mehdi, A.B. Peroxynitrite-mediated oxidative protein modifications. FEBS Lett. 1995, 364, 279-282, doi:10.1016/0014-5793(95)00307-u.

23. Shih, Y. Flow injection analysis of zinc pyrithione in hair care products on a cobalt phthalocyanine modified screen-printed carbon electrode. Talanta 2004, 62, 912-917, doi:10.1016/j.talanta.2003.10.039.

24. Kumar, P.; Kumar, A.; Sreedhar, B.; Sain, B.; Ray, S.S.; Jain, S.L. Cobalt Phthalocyanine Immobilized on Graphene Oxide: An Efficient Visible-Active Catalyst for the Photoreduction of Carbon Dioxide. Chem. - A Eur. J. 2014, 20, 6154-6161, doi:10.1002/chem.201304189.

25. Tackley, D.R.; Dent, G.; Smith, W.E. IR and Raman assignments for zinc phthalocyanine from DFT calculations. Phys. Chem. Chem. Phys. 2000, 2, 3949-3955, doi:10.1039/b0050911.

26. Foster, C.W.; Pillay, J.; Metters, J.P.; Banks, C.E. Cobalt Phthalocyanine Modified Electrodes Utilised in Electroanalysis: Nano-Structured Modified Electrodes vs. Bulk Modified Screen-Printed Electrodes. Sensors 2014, 14, 21905-21922, doi:10.3390/s141121905.

27. Kozub, B.R.; Compton, R.G. Voltammetric studies of the redox mediator, cobalt phthalocyanine, with regard to its claimed electrocatalytic properties. Sensors Actuators B: Chem. 2010, 147, 350-358, doi:10.1016/j.snb.2010.02.062.

28. Herold, S.; Exner, M.; Boccini, F. The Mechanism of the Peroxynitrite-Mediated Oxidation of Myoglobin in the Absence and Presence of Carbon Dioxide. Chem. Res. Toxicol. 2003, 16, 390-402, doi:10.1021/tx0255951.

29. Rehmann, F.-J. Mechanistic studies of the nitrogen monoxide-and nitrite-mediated reduction of ferryl myoglobin and ferryl hemoglobin. Diss., Naturwissenschaften ETH Zürich, Nr. 14805, 2002, 2002,. 
30. Dashteh, M.; Safaiee, M.; Baghery, S.; Zolfigol, M.A. Application of cobalt phthalocyanine as a nanostructured catalyst in the synthesis of biological henna-based compounds. Appl. Organomet. Chem. 2019, 33, e4690, doi:10.1002/aoc.4690.

31. Møinichen, C. Microfluidic flow cells for studies of electrochemical reactions. 2012.

32. Mason, R.P.; Jacob, R.F.; Corbalan, J.J.; Szczesny, D.; Matysiak, K.; Malinski, T. The favorable kinetics and balance of nebivolol-stimulated nitric oxide and peroxynitrite release in human endothelial cells. BMC Pharmacol. Toxicol. 2013, 14, 48, doi:10.1186/2050-6511-14-48.

33. Cortés, J.S.; Granados, S.G.; Ordaz, A.A.; Jiménez, J.A.L.; Griveau, S.; Bedioui, F. Electropolymerized Manganese Tetraaminophthalocyanine Thin Films onto Platinum Ultramicroelectrode for the Electrochemical Detection of Peroxynitrite in Solution. Electroanal. 2007, 19, 61-64, doi:10.1002/elan.200603703.

(C) 2020 by the authors. Submitted for possible open access publication under the terms and conditions of the Creative Commons Attribution (CC BY) license (http://creativecommons.org/licenses/by/4.0/). 